\title{
IPTEKS PENGENDALIAN INTERN ASET TETAP PADA PT. LUMBUNG BERKAT
} INDONESIA

\author{
Jesella Lourina Makaluas ${ }^{1}$, Winston Pontoh $^{2}$ \\ 1,2Program Studi Pendidikan Profesi Akuntansi, Fakultas Ekonomi dan Bisnis, Universitas Sam Ratulangi, Jl. \\ Kampus Bahu, Manado, 95115, Indonesia \\ email : orinmakaluas@gmail.com
}

\begin{abstract}
ABSTRACK
PT Lumbung Berkat Indonesia, as a company entity engaged in construction, of course, this company has various types of fixed assets. The Company's fixed assets should be secured by means of internal controls of fixed assets that will oversee, control costs incurred to acquire fixed assets, increase or extend the fixed asset's useful life and increase operational contribution and productive capacity of fixed assets in order to safeguard the company's property. Based on the research that has been done at PT Lumbung Berkat Indonesia and the existing discussion, the conclusion that can be taken is that the internal control of fixed assets will run efficiently if the points that exist in the elements of control environment, risk assessment, control activities, related information, and monitoring has been well executed amongst companies to perform physical matching of fixed assets, appropriate division of functions and responsibilities, separating expenditures of income and expenses, following insurance against fixed assets, creating audit committees and implementing the abolition and disposal of fixed assets. Suggestions for better companies to explore the knowledge and application of internal control of good fixed assets for corporate activities to run effectively and efficiently and the presentation of financial statements and information about the company's fixed assets is accurate and reliable.
\end{abstract}

Keywords: Internal Control, Fixed Assets

\section{PENDAHULUAN}

Tujuan utama perusahaan adalah memperoleh laba yang optimal sesuai dengan pertumbuhan perusahaan dalam jangka panjang, sehingga perusahaan dapat mempertahankan kelangsungan hidupnya. Dalam menjalankan aktivitas usaha maupun operasionalnya, perusahaan memerlukan aktiva tetap, seperti peralatan, perabotan, mesinmesin, dan bangunan. aktiva tetap mempunyai masa manfaat lebih dari satu periode akutansi, maka dana yang dikeluarkan guna memperoleh aktiva tetap tersebut harus dialokasikan dan biaya atas umur manfaat aktiva tetap juga harus dijadikan beban yang nantinya diperbandingkan dengan penghasilan yang diperoleh untuk tahun yang berjalan. Perhitungan fisik persediaan aktiva tetap harus dilakukan secara periodik dalam rangka memeriksa keakuratan catatan akuntansi. Pemeriksaan semacam itu ditujukan untuk mendeteksi aktiva tetap yang telah hilang, usang, atau rusak. Oleh karena itu, pengendalian yang baik dari segi akuntansi atas aktiva tetap mutlak diperlukan untuk mengamankan aktiva tetap tersebut.

Salah satu cara untuk mengamankan aktiva tetap yang dimiliki adalah dengan adanya pengendalian intern. Dengan adanya pengendalian intern yang baik juga dapat memberikan suatu informasi laporan keuangan perusahaan yang mencerminkan nilai yang benar dari suatu aset tetap tersebut. PT Lumbung Berkat Indonesia, sebagai entitas perusahaan yang bergerak dalam bidang konstruksi, tentunya perusahaan ini memiliki berbagai jenis aktiva tetap. Salah satu cara untuk mengamankan aktiva tetap yang dimiliki adalah dengan adanya pengendalian intern. Pada pengendalian intern ini dirancang prosedur perolehan, pencatatan, dan 
penghentian aktiva tetap. Dari latar belakang diatas, maka penulis tertarik mengambil judul "Analisis Pengendalian Intern Aset Tetap di PT Lumbung Berkat Indonesia.

\section{LANDASAN TEORI}

2.1. Komponen Pengendalian Internal Committee of Supporting Organization of the Tredway Commission (COSO)

Menurut COSO dalam buku Karyono (2013:3), pengendalian intern terdiri atas 5 unsur yaitu:

1. Lingkungan Pengendalian (Control Environment)

2. Penilaian Risiko

3. Aktivitas Pengendalian

4. Informasi dan Komunikasi (information and communication)

5. Pemantauan (monitoring)

\subsection{Perancangan Pengujian Pengendalian Internal}

Jenis pengujian pengendalian yang dapat dipilih auditor dalam pelaksanaan pengujian pengendalian adalah:

1. Permintaan keterangan

2. Pengamatan

3. Inspeksi

4. Pelaksanaan kembali.

\section{METODE DAN TEKNIK PENERAPAN IPTEKS}

\subsection{Metode Penerapan Ilmu Pengetahuan, Teknologi dan Seni}

Metode ipteks yang diterapkan adalah struktur pengendalian intern aktiva tetap yang efektif menurut COSO.

\subsection{Teknik Penerapan Ilmu Pengetahuan, Teknologi dan Seni}

Teknik ipteks yang diterapkan adalah penerapan struktur pengendalian intern aktiva tetap yang efektif (menurut COSO) yakni 5 unsur: Lingkungan pengendalian (control environment), Penaksiran risiko (risk assessment), Aktivitas pengendalian (control activities), Informasi dan Komunikasi (information and communication), Pemantauan (monitoring).

\section{PEMBAHASAN}

\subsection{Gambaran Objek Penerapan Ipteks}

PT. Lumbung Berkat Indonesia berkedudukan di Manado, didirikan berdasarkan Akta Nomor 28. Tanggal 29 Januari 2010 dari Notaris : Ivonne Yuliet Pesik, SH, Notaris di Manado, dan telah mendapat pengesahan dari Kementerian Hukum dan Hak Asasi Manusia (HAM) Republik Indonesia Nomor : AHU-17904.AH.01.01 Tahun 2010, tanggal 09 April 2010.

Berdasarkan Akte pendirian Nomor 28. Tanggal 29 Januari 2010, Maksud dan Tujuan perseroan adalah melaksanakan kegiatan usaha sebagai berikut: bergerak dalam bidang kontraktor, bergerak dalam bidang jasa konstruksi, bergerak dalam bidang perdagangan umum., bergerak dalam bidang pengadaan, menjalankan usaha dalam bidang kontraktor terutama pemborongan, baik perencanaan, pelaksanaan maupun pengawasan atas bangunan, gedung, jalan, jembatan.

\subsection{Pengendalian intern aktiva tetap di PT Lumbung Berkat Indonesia}

Struktur yang dianut oleh PT Lumbung Berkat Indonesia berbentuk lini dengan 3 bagian utama yaitu bagian keuangan dan pembukuan, bagian operasional dan bagian perpajakan dan hrd. PT Lumbung Berkat Indonesia menetapkan program pelatihan (training) 1 bulan, aset tetap yang dibeli diotorisasi oleh direktur utama kemudian dilakukan 
penganggaran oleh bagian keuangan, PT Lumbung Berkat Indonesia mengukur aset tetapnya sebesar harga perolehan aset tetap pada saat terjadinya (metode biaya historis) yakni aktiva tetap diukur sebesar harga perolehan aktiva tetap kemudian dikurangi dengan akumulasi penyusutan, metode penyusutan aset tetap menggunakan metode penyusutan garis lurus yang dimulai dari tahun $2011 \mathrm{~s} / \mathrm{d}$ 2016, perbaikan aset tetap diotorisasi oleh operasional dan direktur utama, PT Lumbung Berkat Indonesia mengakui pengeluaran pemeliharaan dan perbaikan sebagai beban. Perusahaan tidak melakukan pengujian dan pengukuran terhadap aset tetap. Tidak pernah dilakukan pencocokan aset tetap secara fisik dengan catatan aset tetap. Perusahaan tidak melakukan pelepasan aset tetap.

\subsection{Pembahasan}

Pengendalian intern aktiva tetap dalam perusahaan akan berjalan dengan efektif dan efisien maka perusahaan harus melaksanakan 5 unsur pengendalian aktiva tetap yakni mengenai

1. lingkungan pengendalian. Dalam lingkungan pengendalian perusahaan harus menetapkan corak suatu perusahaan seperti: Perusahaan harus terlebih dahulu menetapkan tujuan perusahaan, agar segala sesuatu yang dilaksanakan bisa terarah. Perusahaan terlebih dahulu harus ada falsafah dan filosofih perusahaan. Perusahaan harus menetapkan praktek dan kebijakan karyawan yang sesuai misalkan kebijakan dan praktik pembinaan SDM yang berhubungan dengan aktiva tetap, perusahaan harus memberikan training dengan waktu yang memadai minimal 3 bulan. Perusahaan harus menetapkan struktur organisasi yang baik sesuai bagian-bagiannya yang tentunya didalam terkait wewenang dan tanggung jawab. Misalkan perusahaan harus memisahkan fungsi accounting dan fungsi finance. PT Lumbung Berkat Indonesia sebenarnya harus ada bagian gudang yang akan menjaga dan mengupdate informasi administrasi mulai dari office supply, dan stationaries, yang memegang peranannya dalam pengadaan dan pengeluaran (pemakaian) aktiva tetap sesuai permintaan dan kebutuhan proyek. Perusahaan harus ada Komite audit agar supaya laporan keuangan dan kebijakan-kebijakan mengenai aktiva tetap itu telah sesuai dengan standarisasi yang berlaku dan datanya akurat.

2. Penilaian resiko. Dalam penilaian resiko, perusahaan harus melakukan pengukuran/pengujian aktiva tetap untuk menentukan nilai wajar pasar ketika aktiva tetap akan dijual, agar nilai aktiva tetap benar adanya. Perusahaan juga harus melakukan pemisahan antara pengeluaran pendapatan dan beban agar penyajian laporan keuangan itu wajar dan dapat diandalkan.

3. Aktivitas pengendalian. Perusahaan harus mereview apakah prosedur dan kebijakan mengenai aktiva tetap telah dilaksanakan seperti perusahaan harus melakukan review kinerja (kerja dan kebijakan mengenai aktiva tetap): Perusahaan harus mereview apakah sistem otorisasi terhadap aktiva tetap di perusahaan telah berjalan dengan sesuai. Contoh untuk otorisasi transaksi perolehan, penjualan dan penghentian pemakaian aktiva tetap perusahaan harus melaksanakan itu oleh lebih dari unit organisasi yang bekerja secara independen. Perusahaan harus membuat surat order pembelian yang merupakan tanggung jawab dari bagian pembelian yang akan memilih pemasok dan menerbitkan surat order pembelian untuk pengadaan aktiva tetap yang tentunya seluruh pembelian aktiva tetap tidak terlepas dari otorisasi langsung oleh direktur utama. Untuk transaksi perolehan aktiva tetap, perusahaan harus mempercayakan diotorisasi langsung oleh bagian gudang yang akan menenerima barang tentunya disposisi oleh direktur utama, setelah itu di catat pada bagian pembukuan yang akan membuat daftar aktiva tetap berserta jurnal dan metode penyusutan aktiva tetap dan setelah itu untuk urusan pengeluaran dan penerimaan sejumlah uang ditangani langsung oleh bagian keuangan. Perusahaan membuat surat 
permintaan otorisasi reparasi aktiva tetap yang dibuat oleh bagian operasional/pelaksana proyek yang menyesuaikan dengan data penyusutan dari bagian pembukuan yang kemudian diotorisasi oleh direktur utama. Perusahaan menerbitkan surat perintah kerja harus diotorisasi oleh kepala departemen yang bersangkutan misalkan bagian operasional/pelaksana. Perusahaan harus mereview pengendalian fisik dan pengawasan terhadap aset tetap. Perusahaan harus memastikan keadaan aset tetap secara fisik dengan melakukan pencocokan aktiva tetap minimal dilakukan setahun sekali, agar supaya bisa terlihat keaadaan aktiva tetap yang sebenarnya. Perusahaan harus mereview mengenai kebijakan aktiva tetap. Perusahaan harus mengikuti asuransi untuk seluruh aktiva tetap perusahaan karena mengingat perusahaan adalah perusahaan konstruksi, yang aktiva tetapnya yang memiliki nilai cukup besar dan rawan kecelakaan, agra supaya jika dalam beberapa tahun tidak terjadi hal-hal yang tidak diinginkan pada aktiva tetap, maka sebaiknya perusahaan harus menutup asuransi aktiva tetap, dan hasil dari penutupan asuransi aktiva tetap tersebut digunakan untuk penambahan aktiva tetap sesuai dengan kebutuhan dari proyek. Perusahaan juga harus melaksanakan penghapusan dan pelepasan aset tetap karena aset tetap yang ada dalam perusahaan konstruksi belum tentu bisa dipakai selamanya, bisa saja aset tetap tersebut usang dan bisa membahayakan karyawan jika menggunakan aset tetap yang sudah tidak proporsional lagi.

4. Perusahaan harus mengidentifikasi informasi dan komunikasi tentang aktiva tetap yang diberikan untuk para pengguna informasi seperti metode penyusutan aktiva tetap perusahaan yang efisien dilaksanakan secara continue setiap tahun beserta keseluruhan daftar aktiva tetap perusahaan(aktiva tetap yang ada diproyek dan aktiva tetap yang ada dalam kantor)

5. Perusahaan harus mengawasi aktiva tetap dari perolehan aktiva tetap dengan buget yang telah dianggarkan, pencatatan aktiva tetap perusahaan apakah sudah benar, bagian-bagian yang mengotorisasi aktiva tetap, pengeluaran-pengeluaran aktiva tetap perusahaan, penyusutan aktiva tetap perusahaan berjalan secara konsisten dari tahunketahun, dan asuransi aktiva tetap, sampai pada penghapusan dan pelepasan aktiva tetap.

\section{KESIMPULAN DAN SARAN}

\subsection{Kesimpulan}

Pengendalian intern aktiva tetap di PT Lumbung Berkat Indonesia akan berjalan dengan efisien jika point-point yang ada dalam unsur lingkungan pengendalian, penilaian resiko, aktivitas pengendalian,informasi yang terkait,dan pemantauan telah dilaksakan dengan baik.

\subsection{Saran}

Perlunya pengetahuan dan penerapan tentang pengendalian intern aktiva tetap yang baik agar aktivitas perusahaan berjalan secara efektif dan efisien dan penyajian laporan keuangan serta informasi-informasi mengenai aktiva tetap perusahaan itu akurat dan dapat dipercaya.

\section{DAFTAR PUSTAKA}

Hery. 2014. Akuntansi Aset, Liabilitas, dan Ekuitas.Penerbit PT. Gramedia Widiasarana Indonesia. Jakarta.

Erwin Budiman. 2016. Analisis Pengendalian Intern Aset Tetap pada PT. Hasjrat Multifinance

Cabang Manado. Jurnal Hasil Reset Profesi Akuntansi Unsrat. 
Andreas Indra Cahyadi. 2013. Analisis Pengujian Pengendalian Aktiva Tetap dalam Mendeteksi Kehilangan Aktiva Tetap pada Stikes Perdhaki Charitas Palembang. Jurnal STMIK GI MDP

Karyono. 2013. Forensic Fraud. Penerbit CV Andi Offset. Yogyakarta

Mulyadi.2013. Sistem Akuntansi. Salemba Empat, Edisi 3. Yogyakarta.

T Trimaryadi. 2007. Peranan Pemeriksaan Internal Terhadap Efektivitas Pengendalian Intern Aktiva Tetap pada Perusahaan Daerah Air Minum (PDAM) Kota Bandung (studi kasus pada PDAM Kota Bandung). Jurnal Widyatama. 2540 